which may involve a healthy modesty and ability to share and even to let go.

1 Burns T. The dog that failed to bark. Psychiatrist 2010; 34: 361-3.

Andrew Blewett is Consultant Psychiatrist, Devon Partnership NHS Trust, email: andrew.blewett@nhs.net

doi: $10.1192 /$ pb.34.12.538

\section{Two heads are better than one}

An article starting with a quote from Sherlock Holmes always grabs my attention and Burns' article is no exception. ${ }^{1}$

We made the in-patient/out-patient split in Greenwich in 2006, which resulted in my relinquishing my in-patient work. Initially, I was not at all keen on the idea, for the very reasons laid out by Burns. As time has gone on, however, I have completely changed my mind.

The main positive feature for me is that one has the benefit of a very experienced consultant colleague reviewing the case, including the diagnosis and the management plan. When there is agreement, I feel reassured and move on with improved confidence. When there is a difference of views, I have the opportunity to examine what is being said and to learn from it.

I thought many patients would hate it, but in the 4 years that have elapsed since the change, only one or two have complained to me about it. It has been a helpful change.

1 Burns T. The dog that failed to bark. Psychiatrist 2010; 34: 361-3.

Phil Steadman is Consultant General Adult Psychiatrist, Greenwich Recovery Team, Oxleas NHS Foundation Trust, London, email: phil.steadman@oxleas.nhs.uk

doi: $10.1192 / \mathrm{pb} .34 .12 .539$

\section{Towards integrated care in Europe}

The split responsibility for in-patient and out-patient care is one of the most serious problems facing mental healthcare in Europe. It is a major obstacle in the continuity of care, particularly with severely mentally ill patients.

I have been involved in mental health services research for 30 years. During that time, I have observed increasing efforts to overcome this split responsibility. There are several ongoing evaluations of 'integrated care' all over Europe, which have been developed to overcome this divide. Britain has always set a good example in integrated care and it would be a great pity if the NHS were to abandon this well-accredited approach.

Wulf Rössler is Professor of Clinical and Social Psychiatry, Psychiatric University Hospital Zurich, Switzerland, email: roessler@dgsp.uzh.ch doi: $10.1192 / p b .34 .12 .539 a$

\section{Do we stand by the values upon which the College was founded?}

The association between the non-restraint movement and the formation of the Royal College of Psychiatrists has never been formally acknowledged in either current or past literature. This movement was a significant step in the humane treatment of patients within the psychiatric system and a focus point for the development of other forms of treatment for aggression and mental disorder.

The movement originated in York Asylum in the early 1800s, started by Pinel and Tuke, and was then taken up by Lincoln Asylum's lead physician, Edward Charlesworth. From 1828, also the time of Parliament attempts at passing legislation to improve monitoring of madhouses, Lincoln Asylum had gradually reduced the use of mechanical restraints, until their complete abolition in $1838 .{ }^{1}$ By 1839 , interest had been generated, and Dr John Connolly visited from Hanwell Asylum in Middlesex. After witnessing Lincoln's progress, Connolly set about abolishing the use of mechanical restraints in Hanwell. ${ }^{2}$ By 1841, Lincoln was not the only asylum to abolish the use of restraints: Hanwell, Montrose and Northampton (now St Andrews Hospital) had joined the nonrestraint movement. ${ }^{3}$

In early 1841, Samuel Hitch, resident superintendent of the Gloucestershire General Lunatic Asylum, proposed the establishing of an association of 'Medical Gentlemen connected with Lunatic Asylums'. ${ }^{4}$ He sent a circular to 88 resident medical superintendents and visiting physicians in 44 asylums in June 1841 , requesting their participation in his proposed association. The first annual meeting of the Association of Medical Officers of Asylums and Hospitals for the Insane took place on 4 November 1841, where it was announced: 'The members here present have the greatest satisfaction in recording their appreciation of, and in proposing a vote of thanks to those gentlemen who are now engaged in endeavouring to abolish [mechanical restraint] in all cases.' ${ }^{4}$

This association later became the Royal College of Psychiatrists (1971) and this clear statement supporting the abolishment of the use of mechanical restraints heralded a new era.

The use of mechanical restraints remains current given the specific references in both the Mental Health Act Code of Practice and National Institute for Health and Clinical Excellence guidance, despite the extremely limited evidence base. It is helpful to be reminded that the College began with such benevolent principles: challenging the status quo and striving for the very best for our patients.

1 Walk A. Lincoln and non-restraint. Br J Psychiatry 1970; 117: 481-95.

2 Suzuki A. The politics and ideology of non-restraint: the case of the Hanwell Asylum. Med Hist 1995; 39: 1-17.

3 Smith L. 'The Great Experiment': the place of Lincoln in the history of psychiatry. Lincolnshire Hist Archaeol 1995; 30: 55-62.

4 Bewley T. Madness to Mental Illness: A History of the Royal College of Psychiatrists. RCPsych Publications, 2008.

Jaspreet Singh Phull is ST6 in Forensic Psychiatry, Nottinghamshire Healthcare NHS Trust, Leicester, UK, email: jas.phull@nottshc.uhc.uk doi: $10.1192 / p b .34 .12 .539 b$

\section{Defining coercion}

To define coercion as a subjective response to a particular intervention that is an unfortunate but necessary part of the care of people with psychiatric illness is astonishing! ${ }^{1}$ This Orwellian definition cannot go unchallenged. 